\title{
NONLINEAR ERGODIC THEOREMS FOR NONEXPANSIVE MAPPINGS IN HILBERT SPACES
}

\author{
By Norimichi Hirano and Wataru TAKahashi
}

\section{$\S 1$. Introduction.}

Let $C$ be a closed convex subset of a Hilbert space $H$ and $T$ be a mapping of $C$ into itself. $T$ is said to be asymptotically nonexpansive if for each $x, y \in C$,

$$
\left\|T^{\imath} x-T^{\imath} y\right\| \leqq\left(1+\alpha_{\imath}\right)\|x-y\| \quad \text { for } \imath=1,2, \cdots,
$$

where $\lim \alpha_{\imath}=0$. In particular if $\alpha_{\imath}=0, i=1,2, \cdots, T$ is said to be nonexpansive. In [1], Baillon proved the first nonlinear ergodic theorem: Let $C$ be a closed convex subset of a real Hilbert space $H$ and $T$ be a nonexpansive mapping of $C$ into itself. If $T$ has a fixed point in $C$, then for each $x$ in $C$,

$$
A_{n}(x)=\frac{1}{n}\left(x+T x+\cdots+T^{n-1} x\right)
$$

converges weakly to a fixed point of $T$. Brèzis and Browder [3] extended this theorem to general averaging processes

$$
B_{n}(x)=\sum_{k=0}^{\infty} a_{n, k} T^{k} x\left(0 \leqq a_{n, k}, \sum_{k=0}^{\infty} a_{n, k}=1\right) .
$$

The argument there was very simple and elegant.

In this paper, at first, we extend Baillon's theorem to asymptotically nonexpansive mappings and we prove that the converse of Baillon's theorem is also true; if for each $x$ in $C, A_{n}(x)$ converges weakly to a point in $C$, then $T$ has a fixed point in $C$. Moreover, we obtain nonlinear ergodic theorems for a family $\left\{T_{t}: 0 \leqq t<\infty\right\}$ of mappings on $C$ satisfying some conditions. Finally, a nonlinear ergodic theorem for a commutative semigroup of nonexpansive mappings on $C$ is given by using the asymptotic center defined in Lim's paper [7].

The authors wish to express their hearty thanks to Professor Hisaharu Umegaki for many kind suggestions and advice.

\section{$\S 2$. Ergodic theorems for nonlinear mappings.}

Let $H$ be a real Hilbert space and $C$ be a closed convex subset of $H$. Let

Received July 28, 1977. 
$T$ be a mapping from $C$ into itself, then we define

$$
A_{n} x=\frac{1}{n} \sum_{k=0}^{n-1} T^{k} x \quad \text { for every } \quad x \in C .
$$

Let $D \subset H$. We denote by $\bar{D}$ the closure of $D$, by $\operatorname{coD}$ the convex hull of $D$ and by $\delta(D)$ the diameter of $D$. Let $T$ map $C$ into $H$, then we denote by $R(T)$ the range of $T$ and by $F(T)$ the set of fixed points of $T$. Let $C$ be a nonempty closed convex subset of a Hilbert space $H$, and $\left\{x_{\alpha}: \alpha \in A\right\}$ be a bounded net in C. Then, we define:

$$
\begin{aligned}
& r_{\alpha}(x)=\sup \left\{\left\|x-x_{\beta}\right\|: \beta \geqq \alpha\right\}, \\
& r(x)=\inf \left\{r_{\alpha}(x): \alpha \in A\right\}, \\
& r=\inf \{r(x): x \in C\} .
\end{aligned}
$$

The set $\{x \in C: r(x)=r\}$ will be called the asymptotic center of $\left\{x_{\alpha}: \alpha \in A\right\}$ in $C$. This definition is due to $\operatorname{Lim}[7]$. From the above definition, the asymptotic center of $\left\{x_{\alpha}: \alpha \in A\right\}$ in $C$ is a single-element set $\{x\}$ in $C$ such that

$$
\limsup _{\alpha}\left\|x-x_{\alpha}\right\|=\inf \left\{\limsup _{\alpha}\left\|y-x_{\alpha}\right\|: y \in C\right\} .
$$

We write $x_{n} \rightarrow x$ to indicate that the sequence of vectors $\left\{x_{n}\right\}$ converges weakly to $x$; as usual $x_{n} \rightarrow x$ will symbolize (strong) convergence.

THEOREM 1. Let $C$ be a closed convex subset of a real Hilbert space $H$, and $T$ be a mapping on $C$ such that for each $z \in C,\left\{T^{n} z\right\}$ is bounded and for each $x, y \in C$,

$$
\left\|T^{\imath} x-T^{\imath} y\right\| \leqq\left(1+\alpha_{\imath}\right)\|x-y\|,
$$

where $\lim \alpha_{i}=0$. Then for each $x$ in $C, A_{n} x$ converges weakly to a fixed point of $T$.

We need three lemmas to prove Theorem 1 .

Lemma 1. Let $C$ and $T$ satısfy the same assumptions as in Theorem 1. Let $x \in C$ and $\varepsilon>0$. Then there exists $K_{0}>0$ such that for each $m \geqq K_{0}$, there is $N_{m}>0$ satısfying

$$
\left\|A_{n} x-T^{m} A_{n} x\right\|<\varepsilon \quad \text { for all } n \geqq N_{m} .
$$

Proof. For any $u$ in $H$,

$$
\begin{aligned}
\left\|A_{n} x-u\right\|^{2} & =\left\|\frac{1}{n} \sum_{k=0}^{n-1}\left(T^{k} x-u\right)\right\|^{2} \\
& =\frac{1}{n^{2}} \sum_{j=0}^{n-1} \sum_{k=0}^{n-1}\left(T^{k} x-u, T^{\jmath} x-u\right) .
\end{aligned}
$$

Since $2\left(T^{k} x-u, T^{\jmath} x-u\right)$ 


$$
=\left\|T^{k} x-u\right\|^{2}+\left\|T^{\jmath} x-u\right\|^{2}-\left\|T^{k} x-T^{\jmath} x\right\|^{2},
$$

we obtain

$$
2\left\|A_{n} x-u\right\|^{2}=\frac{2}{n} \sum_{k=0}^{n-1}\left\|T^{k} x-u\right\|^{2}-\frac{1}{n^{2}} \sum_{k=0}^{n-1} \sum_{j=0}^{n-1}\left\|T^{k} x-T^{\jmath} x\right\|^{2} .
$$

If we choose $u=A_{n} x$ in $(*)$, then

$$
\frac{1}{n^{2}} \sum_{k=0}^{n-1} \sum_{j=0}^{n-1}\left\|T^{k} x-T^{\jmath} x\right\|^{2}=\frac{2}{n} \sum_{k=0}^{n-1}\left\|T^{k} x-A_{n} x\right\|^{2} .
$$

Therefore we obtain that for each $u \in H$,

$$
\left\|A_{n} x-u\right\|^{2}=\frac{1}{n} \sum_{i=0}^{n-1}\left\|T^{\imath} x-u\right\|^{2}-\frac{1}{n} \sum_{i=0}^{n-1}\left\|T^{\imath} x-A_{n} x\right\|^{2} .
$$

If we set $u=T^{k} A_{n} x$ where $k \leqq n$, then

$$
\begin{gathered}
\left\|A_{n} x-T^{k} A_{n} x\right\|^{2}=\frac{1}{n} \sum_{i=0}^{k-1}\left\|T^{\imath} x-T^{k} A_{n} x\right\|^{2}+\frac{1}{n} \sum_{i=k}^{n-1}\left\|T^{\imath} x-T^{k} A_{n} x\right\|^{2} \\
-\frac{1}{n} \sum_{i=0}^{n-1}\left\|T^{\imath} x-A_{n} x\right\|^{2} \\
\leqq \frac{1}{n} \sum_{i=0}^{k-1}\left\|T^{\imath} x-T^{k} A_{n} x\right\|^{2}+\left(1+\alpha_{k}\right)^{2} \frac{1}{n} \sum_{i=0}^{n-k-1}\left\|T^{\imath} x-A_{n} x\right\|^{2} \\
\quad-\frac{1}{n} \sum_{i=0}^{n-1}\left\|T^{\imath} x-A_{n} x\right\|^{2} \\
\leqq \frac{1}{n} \sum_{i=0}^{k-1}\left\|T^{\imath} x-T^{k} A_{n} x\right\|^{2}+\left(2 \alpha_{k}+\alpha_{k}{ }^{2}\right) \frac{1}{n} \sum_{i=0}^{n-k-1}\left\|T^{\imath} x-A_{n} x\right\|^{2} .
\end{gathered}
$$

If we set $d=\delta\left(\left\{T^{n} x: n=1,2, \cdots\right\}\right)$ and $N$ is positive integers,

$$
\left\|T^{\imath} x-A_{n} x\right\|^{2} \leqq d^{2} \quad \text { for all } \imath, n \in N .
$$

For arbitrary $\varepsilon>0$, by the hypothesis, there exists $K_{0}>0$ such that $\left(2 \alpha_{k}+\alpha_{k}{ }^{2}\right)$ $<\varepsilon^{2} / 2 d^{2}$ for all $k \geqq K_{0}$. Therefore if $k \geqq K_{0}$,

$$
\left(2 \alpha_{k}+\alpha_{k}^{2}\right) \cdot \frac{1}{n} \sum_{i=0}^{n-k-1}\left\|T^{2} x-A_{n} x\right\|^{2}<\varepsilon^{2} / 2,
$$

and for $m \geqq K_{0}$, there exists $N_{m}>0$ such that

$$
\frac{1}{n} \sum_{i=0}^{k-1}\left\|T^{\imath} x-T^{m} A_{n} x\right\|^{2}<\varepsilon^{2} / 2 \quad \text { for all } n \geqq N_{m} .
$$

Therefore

$$
\left\|A_{n} x-T^{m} A_{n} x\right\|^{2}<\varepsilon^{2} / 2+\varepsilon^{2} / 2=\varepsilon^{2} .
$$


Lemma 2. Let $C$ and $T$ satisfy the assumptions as in Theorem 1. Let $x \in C$. Suppose that a subsequence $\left\{A_{n_{i}} x\right\}$ of $\left\{A_{n} x\right\}$ converges weakly to a point $y$ in $C$. Then $y$ is a fixed point of $T$.

Proof. Suppose that a subsequence $\left\{A_{n_{i}} x\right\}$ of $\left\{A_{n} x\right\}$ converges weakly to a point $y$ in $C$ and $\left\{T^{k} y\right\}$ does not converge strongly to $y$. Then there exists a subsequence $\left\{T^{k} y\right\}$ of $\left\{T^{k} y\right\}$ such that for a positive number $\varepsilon$,

$$
\left\|T^{k_{2}} y-y\right\| \geqq \varepsilon \quad \text { for all } i \in N \text {. }
$$

Since $\left\{A_{n_{\imath}} x\right\}$ converges weakly to $y$, for each $z$ in $H(z \neq y)$, we have

$$
\lim _{\imath} \inf \left\|A_{n_{i}} x-y\right\|<\lim _{\imath} \inf \left\|A_{n_{\imath}} x-z\right\| .
$$

Let $r=\lim \inf \left\|A_{n_{i}} x-y\right\|$ and choose $\delta>0$ such that $\delta<\sqrt{r^{2}+\varepsilon^{2} / 4}-r$, then there exists a subsequence $\left\{A_{m_{i}} x\right\}$ of $\left\{A_{n_{i}} x\right\}$ such that $\left\|A_{m_{i}} x-y\right\|<r+\delta / 3, \imath \in N$.

While

$$
\begin{aligned}
\left\|A_{m_{i}} x-T^{k} y\right\| & \leqq\left\|A_{m_{i}} x-T^{k} A_{m_{i}} x\right\|+\left\|T^{k} A_{m_{i}} x-T^{k} y\right\| \\
& \leqq\left\|A_{m_{i}} x-T^{k} A_{m_{i}} x\right\|+\left\|A_{m_{i}} x-y\right\|+\alpha_{k}\|x-y\| .
\end{aligned}
$$

By Lemma 1 , there exists $K_{0}>0$ such that if $k \geqq K_{0}$, there exists $N_{k}>0$ satisfying

$$
\left\|A_{n} x-T^{k} A_{n} x\right\|<\delta / 3 \quad \text { for all } n \geqq N_{k} .
$$

While there exists $K_{1}>0$ such that $\alpha_{k} \leqq \delta / 3\|x-y\|$ for all $k \geqq K_{1}$. If we choose $k>0$ such that $\left\|T^{k} y-y\right\| \geqq \varepsilon$ and $k \geqq \max \left(K_{0}, K_{1}\right)$, then

$$
\left\|A_{m_{\imath}} x-T^{k} y\right\|<\delta / 3+\delta / 3+(r+\delta / 3)=r+\delta
$$

for all $m_{i} \geqq N_{k}$. Therefore we have that for all $m_{i} \geqq N_{k}$,

$$
\begin{gathered}
\left\|A_{m_{i}} x-\left(T^{k} y+y\right) / 2\right\|^{2}=2\left\|\left(A_{m_{i}} x-T^{k} y\right) / 2\right\|^{2} \\
+2\left\|\left(A_{m_{i}} x-y\right) / 2\right\|^{2}-\left\|\left(T^{k} y-y\right) / 2\right\|^{2} \\
\leqq \\
\end{gathered}
$$

This contradicts the inequality (**).

Lemma 3. Let $C$ and $T$ satisfy the assumptions as in Theorem 1. Let $x \in C$, then the asymptotic center of $\left\{T^{k} x\right\}$ is a fixed point of $T$.

Proof. Suppose the asymptotic center $x_{0}$ of $\left\{T^{k} x\right\}$ is not a fixed point of $T$. Then there exists a subsequence $\left\{T^{k_{2}} x_{0}\right\}$ of $\left\{T^{k} x_{0}\right\}$ such that for a positive number $\varepsilon,\left\|T^{k_{2}} x_{0}-x_{0}\right\| \geqq \varepsilon$. If we set $r=\lim \sup \left\|T^{k} x-x_{0}\right\|$, then for each $\delta>0$ such that $\delta<\varepsilon^{2} / 2$, there exists $N_{0}>0$ such that

$$
\left\|T^{n} x-x_{0}\right\|^{2} \leqq r^{2}+\delta \quad \text { for all } n \geqq N_{0} .
$$


Then we have

$$
\begin{gathered}
\left\|T^{n} x-\left(T^{k_{2}} x_{0}+x_{0}\right) / 2\right\|^{2}=2\left\|\left(T^{n} x-T^{k_{2}} x_{0}\right) / 2\right\|^{2}+2\left\|\left(T^{n} x-x_{0}\right) / 2\right\|^{2} \\
\quad-\left\|\left(T^{k_{2}} x_{0}-x_{0}\right) / 2\right\|^{2} \\
\leqq \\
\frac{1}{2}\left\{\left(1+\alpha_{k_{i}}\right)^{2}\left\|T^{n-k_{\imath}} x-x_{0}\right\|^{2}+\left\|T^{n} x-x_{0}\right\|^{2}\right\}-\frac{1}{4}\left\|T^{k_{\imath}} x_{0}-x_{0}\right\|^{2} \\
\leqq \\
\frac{1}{2}\left(1+\alpha_{k_{\imath}}\right)^{2}\left\|T^{n-k_{\imath}} x-x_{0}\right\|^{2}+r^{2} / 2+\delta / 2-\frac{\varepsilon^{2}}{4} .
\end{gathered}
$$

Since $\lim _{k} \alpha_{k}=0$, there exists $K_{0}>0$ such that if $k_{i} \geqq K_{0}$,

$$
\lim \sup \left\|T^{n} x-\left(T^{k_{2}} x_{0}+x_{0}\right) / 2\right\|<\lim \sup \left\|T^{n} x-x_{0}\right\| .
$$

This is a contradiction.

Proof of Theorem 1. By the weak compactness of $\overline{c o}\left\{T^{n} x\right\}$, there exists a subsequence $\left\{A_{n_{i}} x\right\}$ of $\left\{A_{n} x\right\}$ which converges weakly to a point $y$ in $C$. By Lemma 2, $y$ is a fixed point of $T$, and $y$ is included in $\bigcap_{n} \overline{c o}\left\{T^{k} x: k \geqq n\right\}$. We shall show that $y$ is the asymptotic center of $\left\{T^{n} x\right\}$. For $u \in F(T)$, we set $d=\lim \inf \| T^{k} x$ $-u \|$. Then for each $\varepsilon>0$, there exists $k>0$ such that $\left\|T^{k} x-u\right\|<d+\varepsilon / 2$. Then there exists $j_{0}>0$ such that

$$
\left\|T^{\jmath+k} x-u\right\| \leqq\left(1+\alpha_{j}\right)\left\|T^{k} x-u\right\| \leqq d+\varepsilon \quad \text { for all } j \geqq \jmath_{0} .
$$

Therefore $\left\{\left\|T^{k} x-u\right\|: k=1,2,3, \cdots\right\}$ converges to $d$. Now suppose that $u$ is an element of $\bigcap_{n} \overline{c o}\left\{T^{k} x: k \geqq n\right\} \cap F(T)$ and $u$ is not equal to $x_{0}$. Then

$$
\begin{aligned}
\lim _{k} \sup \left\|T^{k} x-x_{0}\right\| & =\lim _{k}\left\|T^{k} x-x_{0}\right\|<\lim _{k}\left\|T^{k} x-u\right\| \\
& =\limsup _{k}\left\|T^{k} x-u\right\| .
\end{aligned}
$$

If we set $E=\left\{y \in H:\left\|y-x_{0}\right\| \leqq\|y-u\|\right\} . \quad E$ is a closed convex subset of $H$. By the inequality above, there exists $K_{0}>0$ such that $\left\{T^{k} x: k \geqq K_{0}\right\} \subset E$. Therefore $\overline{c o}\left\{T^{k} x: k \geqq K_{0}\right\} \subset E$. Since $u$ is not included in $E, u \notin \overline{c o}\left\{T^{k} x: k \geqq K_{0}\right\}$. This contradicts the definition of $u$. Hence we obtain that $y$ is the asymptotic center of $\left\{T^{k} x\right\}$. Therefore $\left\{A_{n} x\right\}$ converges weakly to $x_{0}$.

Let $C$ be a closed convex subset of $H$. A mapping $T$ from $C$ into itself is said to be nonexpansive if $\|T x-T y\| \leqq\|x-y\|$ for every $x, y \in C$. The following interesting result was obtained by $[10]$.

LEMMa 4. Let $C$ be a subset of a Hilbert space $H$ and $T$ be a nonexpansive mapping of $C$ into itself. Then the following conditions are equivalent:

(a) $0 \in \overline{R(I-T)}$;

(b) $A_{n} x-A_{n} T x \rightarrow 0$ for every $x \in C$; 
(c) $A_{n} x-A_{n} T x \rightarrow 0$ for every $x \in C$.

Proof. (c) $\Rightarrow$ (a). Since

$$
\begin{aligned}
A_{n} x-A_{n} T x & =\frac{x}{n}-\frac{T^{n} x}{n} \\
& =\frac{1}{n} \sum_{k=0}^{n-1}(I-T) T^{k} x \longrightarrow 0,
\end{aligned}
$$

we obtain $0 \in \overline{c o} R(I-T)$. By Lemma 5 in [10], we have $0 \in \overline{R(I-T)}$. (a) $\Rightarrow$ (b) is obvious from Corollary 1 in $[10]$, and (b) $\Rightarrow(c)$ is obvious.

THEOREM 2. Let $C$ be a closed convex set of $H$ and $T$ be a nonexpansive mapping of $C$ into itself. Then, the following conditions are equivalent.

(a) $\left\{T^{n} x\right\}$ is bounded for some $x \in C$;

(a) $\quad\left\{T^{n} x\right\}$ is bounded for all $x \in C$;

(b) $F(T)$ is nonempty;

(c) for some $x \in C, A_{n} x$ converges weakly to a point in $C$;

(c)' for all $x \in C, A_{n} x$ converges weakly to a point in $C$.

Moreover, if for all $x \in C, P x=\lim _{n \rightarrow \infty} A_{n} x$, then $P$ is a nonexpansive retraction from $C$ onto $F(T)$ satusfying $P T=P T=P$.

Proof. (a) $\Leftrightarrow\left(\right.$ b) was proved by Pazy [10]. (b) $\Rightarrow(a)^{\prime}$ is obvious since $T$ is nonexpansive. $(\mathrm{a})^{\prime} \Rightarrow(\mathrm{c})^{\prime}$ is a direct consequence of Theorem 1. (c) $\Rightarrow$ (b): Suppose that $\left\{A_{n} x\right\}$ converges weakly to a point $y$ for some $x \in C$. Then $\left\{A_{n} x\right\}$ is bounded. By using methods employed in [3], we shall prove that $A_{n} x-T A_{n} x \rightarrow 0$. As in the proof of Lemma 1, we obtain that for any $u$ in $H$,

$$
\left\|A_{n} x-u\right\|^{2}=\frac{1}{n} \sum_{i=0}^{n-1}\left\|T^{2} x-u\right\|^{2}-\frac{1}{n} \sum_{i=0}^{n-1}\left\|T^{\imath} x-A_{n} x\right\|^{2} .
$$

If we set $u=T A_{n} x$ in $\left(^{*}\right)$, we find that

$$
\begin{aligned}
& \| A_{n} x- T A_{n} x \|^{2} \\
&=\frac{1}{n}\left\|x-T A_{n} x\right\|^{2}+\frac{1}{n} \sum_{k=1}^{n-1}\left\|T^{k} x-T A_{n} x\right\|^{2} \quad-\frac{1}{n} \sum_{k=0}^{n-1}\left\|T^{k} x-A_{n} x\right\|^{2} \\
& \leqq \frac{1}{n}\left\|x-T A_{n} x\right\|^{2}+\frac{1}{n} \sum_{k=0}^{n-2}\left\|T^{k} x-A_{n} x\right\|^{2} \\
& \quad-\frac{1}{n} \sum_{k=0}^{n-1}\left\|T^{k} x-A_{n} x\right\|^{2}
\end{aligned}
$$




$$
\begin{aligned}
& =\frac{1}{n}\left\|x-T A_{n} x\right\|^{2}-\frac{1}{n}\left\|T^{n-1} x-A_{n} x\right\|^{2} \\
& \leqq \frac{1}{n}\left\|x-T A_{n} x\right\|^{2} \longrightarrow 0 .
\end{aligned}
$$

Since a Hilbert space satisfies Opial's condition [9], if $y \neq T y$, we obtain

$$
\begin{aligned}
\lim _{n \rightarrow \infty}\left\|A_{n} x-y\right\| & <\varliminf_{n \rightarrow \infty}\left\|A_{n} x-T y\right\| \\
& \leqq \lim _{n \rightarrow \infty}\left(\left\|A_{n} x-T A_{n} x\right\|+\left\|T A_{n} x-T y\right\|\right) \\
& \leqq \lim _{n \rightarrow \infty}\left\|A_{n} x-y\right\| .
\end{aligned}
$$

This is a contradiction. Therefore we have $y=T y . \quad(\mathrm{c})^{\prime} \Rightarrow(\mathrm{c})$ and $(\mathrm{a}) \Leftrightarrow(\mathrm{a})^{\prime}$ is trivial.

It is obvious that $P$ is a retraction of $C$ onto $F(T)$. We shall show that $P$ is nonexpansive. In fact, for all $x, y \in C$, we have

$$
\left(A_{n} x-A_{n} y, P x-P y\right) \leqq\|x-y\|\|P x-P y\| .
$$

So,

$$
\begin{aligned}
\|P x-P y\|^{2} & =\lim _{n}\left(A_{n} x-A_{n} y, P x-P y\right) \\
& \leqq\|x-y\|\|P x-P y\|_{1}
\end{aligned}
$$

Hence, we have $\|P x-P y\| \leqq\|x-y\|$.

Let $A_{n} x \rightarrow y$ and $A_{n} T x \rightarrow y^{\prime}$. Then, since $0 \in R(I-T) \subset \overline{R(I-T)}$, it follows from Lemma 4 that $A_{n} x-A_{n} T x \rightarrow 0$. So, we have $y=y^{\prime}$, and hence $P T=P$. It is obvious that $T P=P$.

\section{§ 3. Ergodic theorems for one-parameter semigroups}

Let $C$ be a closed convex subset of a real Hilbert space $H$, and $\left\{T_{t}: 0 \leqq t<\infty\right\}$ be a family of mappings of $C$ into itself satisfying the following conditions:

(a) $T_{t+s} x=T_{t} T_{s} x \quad$ for all $x \in C$ and all $t, s \geqq 0$;

(b) $T_{0} x=x$ for all $x \in C$;

(c) for every $x \in C, T_{t} x$ is continuous in $t \geqq 0$.

We shall call such a family an one-parameter semigroup of mappings on $C$.

THEOREM 3. Let $C$ be a closed convex subset of a real Hilbert space $H$, and $\left\{T_{t}: 0 \leqq t<\infty\right\}$ be an one-parameter semigroup of mappings of $C$ into itself such that for each $z \in C,\left\{T_{t} z\right\}$ is bounded and for each $x, y \in C$, 


$$
\left\|T_{t} x-T_{t} y\right\| \leqq\left(1+\alpha_{t}\right)\|x-y\| \quad \text { for all } x, y \in C,
$$

where $\lim \alpha_{t}=0$. Then for each $x$ in $C, A_{\lambda} x=\frac{1}{\lambda} \int_{0}^{\lambda} T_{t} x d t$ converges weakly to a common fixed point of mappings $T_{t}, 0 \leqq t<\infty$.

Since we can prove Theorem 3 as in Theorem 1 by using the following two lemmas, we shall omit the proof.

LEMma 5. Let $C$ and $\left\{T_{t}: 0 \leqq t<\infty\right\}$ satisfy the same assumptions as in Theorem 3. Then for each $x \in C$ and $\varepsilon>0$, there exists $t_{0}>0$ which satisfies that for each $t \geqq t_{0}$, there exists $\lambda_{0}>0$ such that

$$
\left\|A_{\lambda} x-T_{t} A_{\lambda} x\right\|<\varepsilon \quad \text { for all } \lambda \geqq \lambda_{0} .
$$

Proof. By the methods in the proof of Theorem 1, we obtain

$$
\left\|A_{\lambda} x-T_{s} A_{\lambda} x\right\|^{2}=\frac{1}{\lambda} \int_{0}^{\lambda}\left\|T_{t} x-T_{s} A_{\lambda} x\right\|^{2} d t-\frac{1}{\lambda} \int_{0}^{\lambda}\left\|T_{t} x-A_{\lambda} x\right\|^{2} d t,
$$

where $s \geqq 0$. So, if $s<\lambda$,

$$
\begin{gathered}
\left\|A_{\lambda} x-T_{s} A_{\lambda} x\right\|^{2}=\frac{1}{\lambda} \int_{0}^{s}\left\|T_{t} x-T_{s} A_{\lambda} x\right\|^{2} d t+\frac{1}{\lambda} \int_{s}^{\lambda}\left\|T_{t} x-T_{s} A_{\lambda} x\right\|^{2} d t \\
\quad-\frac{1}{\lambda} \int_{0}^{\lambda}\left\|T_{t} x-A_{\lambda} x\right\|^{2} d t \\
\leqq \frac{1}{\lambda} \int_{0}^{s}\left\|T_{\lambda} x-T_{s} A_{\lambda} x\right\|^{2} d t+\left(1+\alpha_{s}\right)^{2} \frac{1}{\lambda} \int_{0}^{\lambda-s}\left\|T_{t} x-A_{\lambda} x\right\|^{2} d t \\
\quad-\frac{1}{\lambda} \int_{0}^{\lambda}\left\|T_{t} x-A_{\lambda} x\right\|^{2} d t \\
\leqq \frac{1}{\lambda} \int_{0}^{s}\left\|T_{t} x-T_{s} A_{\lambda} x\right\|^{2} d t+\left(2 \alpha_{s}+\alpha_{s}{ }^{2}\right) \frac{1}{\lambda} \int_{0}^{\lambda-s}\left\|T_{t} x-A_{\lambda} x\right\|^{2} d t .
\end{gathered}
$$

Therefore, the argument in the proof of Lemma 1 completes the proof.

LEMMA 6. Let $C$ and $\left\{T_{t}: 0 \leqq t<\infty\right\}$ satisfy the assumptions as in Theorem 3. Suppose that $x \in C$ and a subsequence $\left\{A_{\lambda_{i}} x\right\}$ of $\left\{A_{\lambda} x\right\}$ converges weakly to $y$. Then $y$ is a common fixed point of mappings $T_{t}, 0 \leqq t<\infty$.

Proof. Suppose that there exists $t>0$ such that $T_{t} y \neq y$. Then there exists a sequence $\left\{k_{\imath}: i=1,2, \cdots\right\}$ such that for a positive number $\varepsilon$,

$$
\left\|T_{t}^{k} i y-y\right\| \geqq \varepsilon \quad \text { for all } i \in N \text {. }
$$

Then the argument in the proof of Lemma 2 completes the proof.

We shall obtain the following lemma by a simple modification of Lemma 1 in $[3]$. 
LEMMA 7. Let $\left\{x_{t}\right\}_{t \geq 0}$ and $\left\{y_{t}\right\}_{t \geqq 0}$ be two sequences in $H, F$ be a nonempty subset of $C_{s}=\overline{c o} \bigcup_{t \geq s}\left\{x_{t}\right\}$. Suppose that

(a) for each $f$ in $F,\left\|x_{t}-f\right\| \rightarrow p(f)<\infty$ as $t \rightarrow \infty$,

(b) $\operatorname{dist}\left(y_{t}, C_{s}\right) \rightarrow 0$ as $t \rightarrow \infty$ for each $s \geqq 0$,

(c) any weak limut of an infinite subsequence $\left\{y_{t_{i}}\right\}$ of $\left\{y_{t}\right\}$ satısfying $t_{1}<t_{2}$ $<t_{3}<\cdots$ and $t_{\imath} \rightarrow \infty$ as $i \rightarrow \infty$ lies in $F$.

Then $\left\{y_{t}\right\}$ converges weakly to a point of $F$.

Proof. We shall prove Lemma 7 by methods employed in [3]. By (a) and (b), there is $t_{0} \geqq 0$ such that $\left\{y_{t}\right\}_{t \geqq t_{0}}$ is bounded. So, it suffices to show that if $y_{t_{\imath}} \rightarrow f$ and $y_{s_{i}} \rightarrow g$ for $t_{1}<t_{2}<t_{3}<\cdots, s_{1}<s_{2}<\cdots, t_{\imath} \rightarrow \infty$ and $s_{\imath} \rightarrow \infty$, then $f=g$.

For each $t \geqq 0$,

$$
\left\|x_{t}-f\right\|^{2}=\left\|x_{t}-g\right\|^{2}+\|f-g\|^{2}+2\left(x_{t}-g, g-f\right) .
$$

For a given $\varepsilon>0$, there exists $m(\varepsilon)$ such that for $t \geqq m(\varepsilon)$,

and

$$
\left|p(g)-\left\|x_{t}-g\right\|^{2}\right|<\varepsilon
$$

$$
\left|p(f)-\left\|x_{t}-f\right\|^{2}\right|<\varepsilon .
$$

Let $K_{\varepsilon}$ be the closed convex set of all $u$ such that

$$
\left|2(u-g, g-f)+p(g)-p(f)+\|g-f\|^{2}\right|<2 \varepsilon .
$$

Then, since

$$
\begin{gathered}
2 \varepsilon>\left|p(g)-\left\|x_{t}-g\right\|^{2}\right|+\left|\left\|x_{t}-f\right\|^{2}-p(f)\right| \\
\geqq \mid p(g)-\left\|x_{t}-g\right\|^{2}+\left\|x_{t}-g\right\|^{2}+\|g-f\|^{2} \\
\quad+2\left(x_{t}-g, g-f\right)-p(f) \mid \\
=\left|2\left(x_{t}-g, g-f\right)+p(g)-p(f)+\|g-f\|^{2}\right|,
\end{gathered}
$$

we obtain $K_{\varepsilon} \supset \bigcup_{t>m(\varepsilon)}\left\{x_{t}\right\}$ and hence $K_{\varepsilon} \supset C_{m(\varepsilon)}$.

By (b), there exists $t_{\varepsilon}$ such that for $t \geqq t_{\varepsilon}$, we can find $u_{t}$ in $C_{m(\varepsilon)}$ such that $\left\|y_{t}-u_{t}\right\| \leqq \varepsilon$. For $t \geqq t_{\varepsilon}$, it follows by $y_{t}=y_{t}-u_{t}+u_{t}$ that

$$
\begin{gathered}
\left|2\left(y_{t}-g, g-f\right)+p(g)-p(f)+\|g-f\|^{2}\right| \\
\leqq 2 \varepsilon+2 \varepsilon\|g-f\| .
\end{gathered}
$$

Since $y_{S_{\imath}} \rightarrow g$, we obtain that

$$
\left|p(g)-p(f)+\|g-f\|^{2}\right|<2 \varepsilon+2 \varepsilon\|g-f\| .
$$

Since $\varepsilon>0$ is arbitrary, it follows that

$$
p(g)+\|g-f\|^{2}=p(f) .
$$


By symmetry,

$$
p(f)+\|g-f\|^{2}=p(g) .
$$

Hence $f=g$.

THEOREM 4. Let $C$ be a closed convex subset of a real Hilbert space $H$ and $\left\{T_{t}: 0 \leqq t<\infty\right\}$ be an one-parameter semigroup of nonexpansive mappings of $C$ into itself. Then the followng conditions are equivalent

(a) $\left\{T_{t} x: 0 \leqq t<\infty\right\} \quad$ is bounded for some $x \in C$;

(a) $\quad\left\{T_{t} x: 0 \leqq t<\infty\right\} \quad$ is bounded for all $x \in C$;

(b) $\bigcap_{t \geqq 0} F\left(T_{t}\right)$ is nonempty;

(c) $\frac{1}{\lambda} \int_{0}^{\lambda} T_{t} x d t$ converges weakly as $\lambda \rightarrow \infty$ for some $x \in C$;

(c) $\frac{1}{\lambda} \int_{0}^{\lambda} T_{t} x d t$ converges weakly as $\lambda \rightarrow \infty$ for all $x \in C$.

Moreover, if for all $x \in C, P x=\lim \frac{1}{\lambda} \int_{0}^{\lambda} T_{t} x d t$, then $P$ is a nonexpansive retraction from $C$ onto $\bigcap_{t \geq 0} F\left(T_{t}\right)$ satısfying

$$
P T_{t}=T_{t} P=P \quad \text { for all } t \geqq 0 \text {. }
$$

Proof. (b) $\Rightarrow(a)^{\prime}$ is obvious since $T$ is nonexpansive. Though (b) $\Rightarrow(c)^{\prime}$ is a direct counsequence of Theorem 3, we shall give its proof by using Lemma 7 . Let $F=\bigcap_{t \geq 0} F\left(T_{t}\right), x_{t}=T_{t} x$ and $y_{\lambda}=\frac{1}{\lambda} \int_{0}^{\lambda} T_{t} x d t$. If $t>t^{\prime}$ and $f \in F$, it follows that

$$
\left\|T_{t} x-f\right\| \leqq\left\|T_{t}, x-f\right\| \text {. }
$$

So, $\left\|T_{t} x-f\right\|$ converges to $p(f)<+\infty$.

Since for each $s \geqq 0$,

$$
\left\|\frac{1}{\lambda} \int_{0}^{\lambda} T_{t} x d t-\frac{1}{\lambda}\left(\int_{0}^{s} T_{s} x d t+\int_{s}^{\lambda} T_{t} x d t\right)\right\| \rightarrow 0, \text { as } \lambda \rightarrow \infty,
$$

we obtain that $\operatorname{dist}\left(y_{\lambda}, C_{s}\right) \rightarrow 0$ as $\lambda \rightarrow \infty$ for each $s \geqq 0$. By methods in the proof of Theorem 1, we obtain that

$$
\begin{aligned}
\left\|y_{\lambda}-T_{s} y_{\lambda}\right\|^{2}= & \frac{1}{\lambda} \int_{0}^{\lambda}\left\|T_{t} x-T_{s} y_{\lambda}\right\|^{2} d t \\
& -\frac{1}{\lambda} \int_{0}^{\lambda}\left\|T_{t} x-y_{\lambda}\right\|^{2} d t .
\end{aligned}
$$

So, if $s<\lambda$, 


$$
\begin{aligned}
\left\|y-T_{s} y_{\lambda}\right\|^{2}= & \frac{1}{\lambda}\left[\int_{0}^{s}\left\|T_{t} x-T_{s} y_{\lambda}\right\|^{2} d t\right. \\
& \left.+\int_{s}^{\lambda}\left\|T_{t} x-T_{s} y_{\lambda}\right\|^{2} d t-\int_{0}^{\lambda}\left\|T_{t} x-y_{\lambda}\right\|^{2} d t\right] \\
= & \frac{1}{\lambda}\left[\int_{0}^{s}\left\|T_{t} x-T_{s} y_{\lambda}\right\|^{2} d t+\int_{0}^{\lambda-s}\left\|T_{s+u} x-T_{s} y_{\lambda}\right\|^{2} d u\right. \\
& \left.-\int_{0}^{\lambda}\left\|T_{t} x-y_{\lambda}\right\|^{2} d t\right] \\
\leqq & \frac{1}{\lambda} \int_{0}^{s}\left\|T_{t} x-T_{s} y_{\lambda}\right\|^{2} d t
\end{aligned}
$$

Since $\left\{T_{t} x: t \geqq 0\right\}$ is bounded, it follows that $\left\|y_{\lambda}-T_{s} y_{\lambda}\right\| \rightarrow 0$ as $\lambda \rightarrow \infty$ for each $s \geqq 0$ and hence (c) in Lemma 7 holds.

Therefore, it follows from Lemma 7 that $\frac{1}{\lambda} \int_{0}^{\lambda} T_{t} x d t$ converges weakly to a point of $F$.

(c) $\Rightarrow$ (b). Suppose that $y_{\lambda}=\frac{1}{\lambda} \int_{0}^{\lambda} T_{t} x d t$ converges weakly to a point $y$ in $C$. Then, as in the proof of (c) $\Rightarrow$ (b) in Theorem 2, we obtain that

$$
\left\|y_{\lambda}-T_{s} y_{\lambda}\right\| \rightarrow 0 \text { as } \lambda \rightarrow \infty \text { for each } s \geqq 0 .
$$

Therefore, it follows that $y \in F=\cap\left\{F\left(T_{t}\right): t \geqq 0\right\}$.

(b) $\Rightarrow$ (a) is obvious.

(a) $\Rightarrow$ (b). Suppose that $\left\{T_{t} x: t \geqq 0\right\}$ is bounded, then it follows that $\left\{y_{\lambda}: \lambda \geqq 0\right\}$ is bounded and $\left\|y_{\lambda}-T_{s} y_{\lambda}\right\| \rightarrow 0$ as $\lambda \rightarrow \infty$ for each $s \geqq 0$. Since $y_{\lambda_{i}} \rightarrow y$ for some subsequence $\left\{y_{\lambda_{2}}\right\}$ of $\left\{y_{i}\right\}$ satisfying $\lambda_{1}<\lambda_{2}<\cdots$ and $\lambda_{2} \rightarrow \infty$, we obtain that

$$
y \in \cap\left\{F\left(T_{t}\right): t \geqq 0\right\} .
$$

Suppose that for any $x$ in $C, \frac{1}{\lambda} \int_{0}^{\lambda} T_{t} x d t$ converges weakly to a point $y$ in $C$. If $P x=y$, it is obvious that $P$ is retraction of $C$ onto $F=\cap\left\{F\left(T_{t}\right): t \geqq 0\right\}$.

Since

$$
\begin{aligned}
\|P x-P y\|^{2} & =\lim _{\lambda}\left(\frac{1}{\lambda} \int_{0}^{\lambda} T_{t} x d t-\frac{1}{\lambda} \int_{0}^{\lambda} T_{t} y d t, P x-P y\right) \\
& \leqq\|x-y\|\|P x-P y\| \quad \text { for all } x, y \in C,
\end{aligned}
$$

$P$ is nonexpansive on $C$.

For any $s \geqq 0$, 


$$
\begin{aligned}
& \frac{1}{\lambda} \int_{0}^{\lambda} T_{t} x d t-\frac{1}{\lambda} \int_{0}^{\lambda} T_{t} T_{s} x d t \\
& =\frac{1}{\lambda} \int_{0}^{\lambda} T_{t} x d t-\frac{1}{\lambda} \int_{s}^{\lambda+s} T_{u} x d u \\
& =\frac{1}{\lambda} \int_{0}^{s} T_{t} x d t-\frac{1}{\lambda} \int_{\lambda}^{\lambda+s} T_{u} x d u \\
& =\frac{1}{\lambda} \int_{0}^{s} T_{t} x d t-\frac{1}{\lambda} \int_{0}^{s} T_{t} T_{\lambda} x d t .
\end{aligned}
$$

Since $\left\{T_{t} z\right\}$ is bounded for each $z$ in $C$,

$$
\frac{1}{\lambda} \int_{0}^{\lambda} T_{t} x d t-\frac{1}{\lambda} \int_{0}^{\lambda} T_{t} T_{s} x d t \rightarrow 0 \text { as } \lambda \rightarrow \infty \text { for each } s \geqq 0 .
$$

Hence we obtain that $P T_{t}=P$ for all $t \geqq 0$. It is obvious that $T_{t} P=P$ for all $t \geqq 0$.

\section{$\S 4$. Ergodic theorem for a commutative semigroup.}

In this section, we shall prove an ergodic theorem for a commutative semigroup of nonexpansive mappings.

LEMMA 8. Let $C$ be a nonempty bounded closed convex subset of a real Hilbert space $H$, and $\left\{x_{\alpha}: \alpha \in A\right\}$ be a net in $C$, then the asymptotic center $x_{0}$ of $\left\{x_{\alpha}: \alpha \in A\right\}$ is an element in $\overline{c o}\left\{x_{\alpha}: \alpha \in A\right\}$.

Proof. Let $z$ be the nearest point to $x_{0}$ in $\overline{c o}\left\{x_{\alpha}: \alpha \in A\right\}$, then

So, we have

$$
\|z-y\| \leqq\left\|x_{0}-y\right\| \quad \text { for all } y \text { in } \overline{c o}\left\{x_{\alpha}: \alpha \in A\right\} .
$$

$$
\begin{aligned}
\lim _{\alpha} \sup \left\|z-x_{\alpha}\right\| & \leqq \lim _{\alpha} \sup \left\|x_{0}-x_{\alpha}\right\| \\
& =\inf \left\{\lim _{\alpha} \sup \left\|y-x_{\alpha}\right\|: y \in C\right\} .
\end{aligned}
$$

Since the asymptotic center is one point, we have $z=x_{0}$. Therefore, $x_{0}$ is in $\overline{c o}\left\{x_{\alpha}: \alpha \in A\right\}$.

Let $\Sigma$ be a commutative semigroup with identity, then $\Sigma s \cap \Sigma t(=s \Sigma \cap t \Sigma) \neq \phi$, for all $s, t \in \Sigma$. So, if we define an order $t \geqq s$ by $t \in \Sigma s, \Sigma$ is a directed set. By methods employed in [1], we shall prove the following lemma.

LEMMA 9. Let $C$ be a bounded closed convex subset of a real Hilbert space $H$, and $\Sigma$ be a commutative semigroup of nonexpansive mappings on $C$. Define $F(\Sigma)=\{x \in C: T x=x$ for all $T \in \Sigma\}$ and let $P_{0}$ be the metric projection of $C$ onto $F(\Sigma)$, then for each $x \in C,\left\{P_{0} T x\right\}_{T \in \Sigma}$ converges strongly to a point $l$ in $F(\Sigma)$. 
Proof. Define $l_{T}=P_{0} T x$ for each $T \in \Sigma$. If $S, T \in \Sigma$ and $S \geqq T$, then there exists $U \in \Sigma$ satisfying $S=U T$. Then

$$
\begin{aligned}
\left\|S x-l_{S}\right\| & =\left\|U T x-l_{U T}\right\| \leqq\left\|U T x-l_{T}\right\| \\
& =\left\|U T x-U l_{T}\right\| \leqq\left\|T x-l_{T}\right\| .
\end{aligned}
$$

Therefore, $\left\{\left\|T x-l_{T}\right\|: T \in \Sigma\right\}$ is a decreasing net. Define $d=\lim _{T}\left\|T x-l_{T}\right\|$ and $\left\|l_{T}-T x\right\|^{2}=d^{2}+\varepsilon_{T}$.

Since

$$
\begin{gathered}
\left\|l_{S}-l_{T}\right\|^{2}=2\left\|l_{S}-S x\right\|^{2}+2\left\|l_{T}-T x\right\|^{2} \\
-\left\|l_{S}+l_{T}-2 S x\right\|^{2}
\end{gathered}
$$

and $\left\|\frac{l_{S}+l_{T}}{2}-S x\right\| \geqq\left\|l_{S}-S x\right\| \geqq d$, we have

$$
\left\|l_{S}-l_{T}\right\|^{2} \leqq 2\left(d^{2}+\varepsilon_{S}\right)+2\left(d^{2}+\varepsilon_{T}\right)-4 d^{2}=2\left(\varepsilon_{T}+\varepsilon_{S}\right) .
$$

Hence, we obtain that $\left\{P_{0} T x\right\}$ converges strongly.

THEOREM 5. Let $C$ be a bounded closed convex subset of a real Hilbert space $H$ and $\Sigma$ be a commutative semigroup of nonexpansive mappings on $C$. Then there exists a nonexpansive retraction $P$ of $C$ onto $F(\Sigma)$ satisfying the following conditions.

(a) $P T=T P=P$ for all $T$ in $\Sigma$;

(b) $P x \in \overline{c o}\{T x: T \in \Sigma\} \quad$ for all $x$ in $C$.

Proof. We shall first show that for $x \in C$, the asymptotic center $x_{0}$ of $\{T x$ : $T \in \Sigma\}$ is a common fixed point of $\Sigma$. For each $U \in \Sigma$,

$$
\begin{aligned}
\lim _{S} \sup _{T \geqq S}\left\|U x_{0}-T x\right\| & =\lim _{S \geqq U} \sup _{T \geqq S}\left\|U x_{0}-U T x\right\| \\
& \leqq \lim _{S} \sup _{T \geqq S}\left\|x_{0}-T x\right\| .
\end{aligned}
$$

Since the asymptotic center is unique, $U x_{0}=x_{0}$ for all $U$ in $\Sigma$. Next we shall show that for each $U \in \Sigma$, the asymptotic center of $\{T x: T \geqq U\}$ in $C$ is $x_{0}$. For each $z \in H$,

$$
\begin{aligned}
\lim _{S} \sup _{T \geq S}\|z-T(U x)\| & =\lim _{S} \sup _{T \geqq S}\|z-U T x\| \\
& =\lim _{S \geqq U} \sup _{T \geqq S}\|z-T x\| \\
& =\lim _{S} \sup _{T \geqq S}\|z-T x\| .
\end{aligned}
$$

So,

$$
\lim _{S} \sup _{T \geqq S}\left\|y_{0}-T(U x)\right\|=\lim _{S} \sup _{T \geqq S}\left\|y_{0}-T x\right\|
$$




$$
\begin{aligned}
& \geqq \lim _{S} \sup _{T \geqq S}\left\|x_{0}-T x\right\| \\
& =\lim _{S} \sup _{T \geqq S}\left\|x_{0}-T(U x)\right\| \\
& \geqq \lim _{S} \sup _{T \geqq S}\left\|y_{0}-T(U x)\right\| .
\end{aligned}
$$

Since the asymptotic center is unique, we obtain $y_{0}=x_{0}$. Now we define a mapping $P$ on $C$ as follows. For each $x \in C, P x$ is the asymptotic center of $\{T x$ : $T \in \Sigma$. Then $P$ is a retraction of $C$ onto $F(\Sigma)$. It follows from the discussion above that $P$ satisfies (a) and (b). Finally, we shall show that $P$ is nonexpansive. As in Lemma 9, define $l_{T}=P_{0} T x$ for each $T \in \Sigma$, and $l=\lim _{T} P_{0} T x$. By the definition of $P_{0}$,

So, we have

$$
\begin{aligned}
\|l-T x\| & \leqq\left\|l-l_{T}\right\|+\left\|l_{T}-T x\right\| \\
& \leqq\left\|l-l_{T}\right\|+\|P x-T x\| .
\end{aligned}
$$

$$
\lim _{S} \sup _{T \geqq S}\|l-T x\| \leqq \lim _{S} \sup _{T \geqq S}\left\|l-l_{T}\right\|+\lim _{S} \sup _{T \geqq S}\|P x-T x\| .
$$

Since $\lim _{T}\left\|l-l_{T}\right\|=0$, by Lemma 9 , we have

$$
\lim _{S} \sup _{T \geqq S}\|l-T x\| \leqq \lim _{S} \sup _{T \geqq S}\|P x-T x\| \text {. }
$$

Since the asymptotic center is unique, $P x=l$. Hence, we obtain

$$
\begin{gathered}
\|P x-P y\|=\lim _{T}\left\|P_{0} T x-P_{0} T y\right\| \leqq \lim _{T}\|T x-T y\| \\
\leqq\|x-y\| .
\end{gathered}
$$

Remark 1. In Theorem 5, we do not know whether 'commutative' can be replaced by 'amenable'.

Remark 2. The following example show that $F(\Sigma) \cap \overline{c o}\{T x: T \in \Sigma\}$ is not necessarly one point.

Let $C=[-2,2]$ and let us define a nonexpansive mapping $T$ on $C$ by

and

$$
T x=-x \quad \text { for } \quad-2 \leqq x<0
$$

$$
T x=x \quad \text { for } 0 \leqq x \leqq 2 .
$$

Then, we have $F(\Sigma) \cap \overline{\mathrm{co}}\left\{T^{n}(-1): n=0,1,2, \cdots\right\}=[0,1]$.

\section{REFERENCES}

[1] BAILlon, J-B., Un theórème de type ergodique pour les contractions non linéaire dans un espace de Hilbert, C. R. Acad. Sci. Paris Sér. A-B 280 (1975), no. 22, Aii, A1511-A1514. 
[2] BARBU, V., Nonlinear semigroups and differential equations in Banach spaces, Noordorff International Publishing, Leyden, The Netherlands, 1976.

[3] BrEzis, H. ANd F.E. Browder, Nonlinear ergodic theorems, Bull. Amer. Math. Soc. 82 (1976), 959-961.

[4] Edelstein, M., The construction of an asymptotic center with a fixed-point property, Bull. Amer. Math. Soc. 78 (1972), 206-208.

[5] K. Goebel AND W.A. KIRK, A fixed point theorem for asymptotically nonexpansive mappings. Proc. Amer. Math. Soc. 35 (1972), 171-174.

[6] Hille, E. ANd R.S. Phillips, Functional analysis and semigroups, Amer. Math. Colloq. Pub. vol. 31, New York (1948).

[7] LIM, T.C., Characterization of normal stracture, Proc. Amer. Math. Soc. 43 (1974), 313-319.

[8] Lim, T.C., A fixed point theorem for families of nonexpansive mappings, Pacific J. Math. 53 (1974), 487-493.

[9] OpIal, Z., Weak convergence of the sequence of successive approximations for nonexpansive mappings in Banach spaces, Bull. Amer. Math. Soc. 73 (1967), 591-597.

[10] PAZY, A., Asymptotic behavior of contractions in Hilbert space, Israel J. Math. 9 (1971), 235-240.

[11」 Takahashi, W., Fixed point theorem for amenable semigroup of nonexpansive mappings, Kōdai Math. Sem. Rep., 21 (1969), 383-386.

[12] Umegaki, H., and W. TaKahashi, A generalization of Goebel and Kirk's fixed point theorem, Sci. Rep. Yokohama National Univ. 21 (1974), 1-4.

Department of Information Sciences,

TOKyo Institiute of TECHNOLOGY 